\title{
MYOSITIS OSSIFICANS PROGRESSIVA-CURRENT CONCEPTS
}

R. K. Rohit ${ }^{1}$, Madhuchandra P2 ${ }^{2}$ Sathish Devadoss ${ }^{3}$, A. Devadoss ${ }^{4}$

\section{HOW TO CITE THIS ARTICLE:}

R K Rohit, Madhuchandra P, Sathish Devadoss, A. Devadoss. "Myositis Ossificans Progressiva-Current Concepts". Journal of Evolution of Medical and Dental Sciences 2014; Vol. 3, Issue 56, October 27; Page: 12843-12847, DOI: $10.14260 /$ jemds/2014/3706

INTRODUCTION: Myositis ossificans progressiva is a severe disabling disorder occurring as a rare sporadic or autosomal dominant disorder. ${ }^{1}$ The incidence is about 1 in 2 million people with no particular predilictions. ${ }^{2}$ It presents clinically with characteristic short great toes and heterotopic ossification involving multiple sites. ${ }^{3}$ Current research points the defect to a receptor of Bone Morphogenic Protein which induces the ossification.

The cumulative effect of the heterotopic ossification leads to severe disability which leads to being wheelchair ridden by the end of the third decade of life and ultimately death due to thoracic insufficiency syndrome. A sharp clinical acumen to identify the disease is essential as it could significantly alter the natural course of the disease and hence, the survival and quality of life of the patient being dependent on it.

CASE REPORT: A 22 year old male patient came with complaints of pain in the right hip and low back ache for 2 months. There was no other significant contributory history. A general survey revealed a hard bony swelling in the dorsal parascapular region and was not arising from the scapula and was in the muscular plane. His great toes were found to be hypoplastic (Fig 1). His hip examination revealed a joint line tenderness and terminal restriction of movements. His neurological examination was normal.

His laboratory investigations were normal. His radiographs revealed arthritic changes in the hip; ectopic ossification in the gluteal region \& paraspinal region; hypoplastic $1^{\text {st }}$ metatarsal and proximal phalanx (Fig 2). CT/MRI showed myositic changes involving the left gluteal region and calcification of interspinous and supraspinous ligaments in the lower thoracic and lumbar spine (Fig 3). He was diagnosed as Myositis Ossificans Progressiva and was started on steroid therapy and followed with maintenance NSAIDs. Patient was relieved of symptoms but swelling persisted. Although having classical features of FOP and in the second decade of life as well as an undiagnosed individual, our patient was relatively free of disability.

DISCUSSION: Fibrodysplasia ossificans progressiva (FOP) is a severely disabling genetically inherited disorder of connective tissue characterized by congenital malformations of the great toes (hallux valgus, malformed first metatarsal) and progressive heterotopic ossification (HO) that forms qualitatively normal bone in characteristic extraskeletal sites. ${ }^{1}$ The most common site of involvement is the dorsal paraspinal region with a progression from the axial to the appendicular skeleton. It is a rare disease with a prevalence of 1 in 2000000 people with no racial or geographical preponderance. ${ }^{2}$

Aetiopathology: The essential defect lies in the gain of function mutation in the BMP 1 Receptor (ACVR1/ALK2). These receptors are extensively found in cartilage and muscular tissues. BMP leads to the cell differentiation and also determines the cell fate and hence leads to an expansion of cartilage elements and causes bony joint fusions in a case of FOP.4,5 An inflammatory environment is 
essential for the development of the heterotopic ossification. The progenitor cells which cause the ossification are of vascular endothelial precursor origins that respond to an inflammatory environment and overacting BMP signaling to differentiate through an enchondral pathway into osteocytes resulting in ectopic ossification. ${ }^{6}$

This explains trauma, viral infections, intramuscular immunizations, injections for dental work acting as triggers due to the inflammation incited in susceptible individuals. Three types of Fibrodysplasia Ossificans Progressiva have been described; Typical, Atypical and Variant types (Table 1).

Clinical Presentation: Neck pain is one of the earliest symptoms. Although an inherited disorder, the only presentation at birth would be malformed toes which are characteristic of this condition. Heterotopic ossification commonly in the paraspinal region that has some relation to an earlier traumatic event can be present. Ossifications in an old injection site or surgical sites are common. Exacerbations or flare ups can spontaneously regress or can cause muscles, ligaments, aponeuroses or fasciae to ossify, even across joints and render them immobile. ${ }^{1}$

The immobility is cumulative and the patient is wheelchair ridden in the third decade of life. Ankylosis of the jaw leads to severe weight loss and the patient progresses to thoracic insufficiency syndrome due to costovertebral malformations with ankylosis of the costovertebral joints, ossification of intercostal muscles, paravertebral muscles and aponeuroses, as well as progressive spinal deformity including kyphoscoliosis or thoracic lordosis. Other skeletal features associated with FOP are short malformed thumbs, clinodactyly, short broad femoral necks, and proximal medial tibial osteochondromas.

Diagnosis: Early diagnosis is of utmost importance. However premature biopsy can exacerbate the pathology or give the wrong diagnosis of a sarcoma and a delayed biopsy can result in missing a sarcoma. Hence, it is essential to identify the ZONE PHENOMENON 7 which is detected at the earliest by a USG.

\section{Zone Phenomenon:}

- The first zone, the most peripheral hypoechoic zone encircles the lesion; contiguous hyperemia can be observed on Doppler USG.

- $\quad$ The second zone is thinner \& hyperechoic and corresponds to ossifications.

- The third zone, central zone is hypoechoic and corresponds to central stromal fibroblastic component.

Classical clinical findings are diagnostic and should be made before the appearance of heterotopic bone through genetic analysis of ACVR1 mutation.8,9. CT, MRI and X-rays are other modalities that can be utilized. There is an $87 \%$ chance of misdiagnosis or delayed diagnosis and inappropriate procedures on the patient due to this can result in significant alteration in the natural course of the disease and this occurs mainly due to lack of physician awareness. ${ }^{10}$

Treatment: Surgical attempts to remove heterotopic bone will provoke explosive new bone growth and should not be attempted. ${ }^{11}$ The management principle revolves around lifestyle modifications and management of exacerbations (Table 2).

Differential Diagnosis: Progressive Osseus Heteroplasia, Aggressive Juvenile Fibromatosis, soft tissue sarcomas, lymphomas and desmoids tumors are a few important ones to consider. 
CONCLUSION: Although AD form of the disease is described, sporadic incidence is more common. Classical features of FOP are short great toes and heterotopic ossification. Vascular endothelial cells are the precursors to osteocytes causing heterotopic ossification. Early diagnosis has a significant bearing on the natural course of the disease. Genetic testing for ACVR1 mutation is definitive and available. Treatment mainly involves lifestyle modification and management of flare ups.

\section{REFERENCES:}

1. Pignolo RJ, Shore EM, Kaplan FS. Fibrodysplasia Ossificans Progressiva: Clinical and Genetic Aspects. Orphanet Journal of Rare Diseases 2011, 6:80.

2. Shore EM, Feldman GJ, Xu M, Kaplan FS. The genetics of fibrodysplasia ossificans progressiva. Clin Rev Bone Miner Metab 2005, 3:201-204.

3. Connor JM, Evans DAP. Fibrodysplasia Ossificans Progressiva. The journal of bone and joint surgery, 1982, VOL. 64-B, No. 1: 76-83.

4. Kaplan FS, Xu M, Seemann P, Connor M, Glaser DL, Carroll L et al. Classic and atypical fibrodysplasia ossificans progressiva (FOP) phenotypes are caused by mutations in the bone morphogenetic Protein (BMP) type I receptor ACVR1. Hum Mutat 2009, 30:379-90.

5. Kaplan FS, Shore EM: Insights from a Rare Genetic Disorder of Extra-Skeletal Bone Formation, Fibrodysplasia Ossificans Progressiva (FOP). Bone. 2008 September; 43 (3): 427-433.

6. Lounev VY, Ramachandran R, Wosczyna MN, Yamamoto M, Maidment ADA, Shore EM, Glaser DL, Goldhamer DJ, Kaplan FS. Identification of Progenitor Cells That Contribute to Heterotopic Skeletogenesis. J Bone Joint Surg Am. 2009; 91: 652-63.

7. Thomas EA, Cassar-Pullicino VN, McCall IW. The role of ultrasound in the early diagnosis and management of heterotopic bone formation. Clin Radiol. 1991; 43: 190-6.

8. Kaplan FS, Xu M, Glaser DL, Collins F, Connor M, Kitterman J, Sillence D, Zackai E, Ravitsky V, Zasloff M, Ganguly A, Eileen M, Shore EM. Early Diagnosis of Fibrodysplasia Ossificans Progressiva. Pediatrics. 2008 May; 121(5): e1295-e1300.

9. Pinzas JG, Wong JEB, Fernández MAP, Espinoza MAR. Fibrodysplasia ossificans progressiva: diagnosis in primary care. Rev Paul Pediatr 2013; 31(1): 124-8.

10. Kitterman JA, Kantanie S, Rocke DM, Kaplan FS. Iatrogenic Harm Caused by Diagnostic Errors in Fibrodysplasia Ossificans Progressiva. Pediatrics 2005; 116: e654-e661.

11. Kaplan FS, Le Merrer M, Glaser DL, Pignolo RJ, Goldsby RE, Kitterman JA et al. Fibrodysplasia ossificans progressiva. Best Pract Res Clin Rheumatol 2008; 22: 191-205.

\section{TABLE 1:}

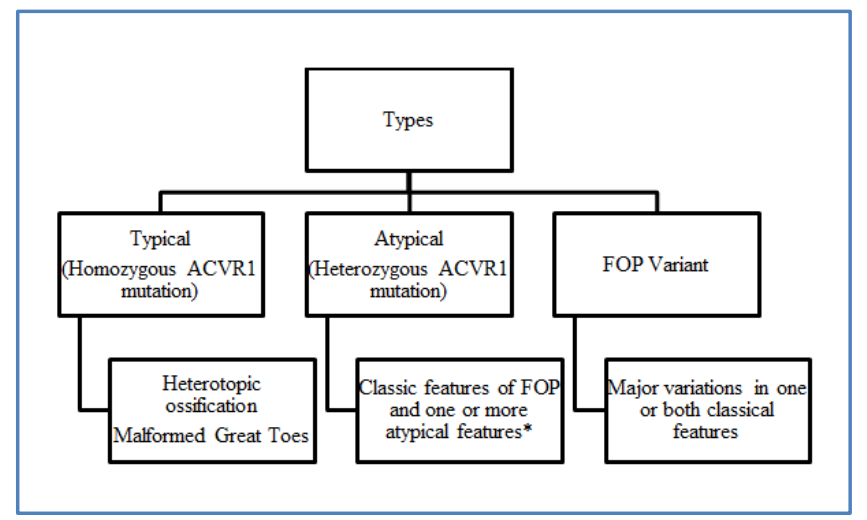




\section{CASE REPORT}

*Intraarticular synovial osteochondromatosis of hips, degenerative joint disease of hips, sparse/thin scalp hair (more prominent in second decade), mild cognitive impairment, severe growth retardation, cataracts, retinal detachment, childhood glaucoma, craniopharygioma, persistence of primary teeth in adulthood, anatomic abnormalities of the cerebellum, diffuse cerebral dysfunction with seizures, polyostotic fibrous dysplasia, primary amenorrhea, aplastic anemia, hypospadias, and cerebral cavernous malformations.

\section{TABLE 2:}
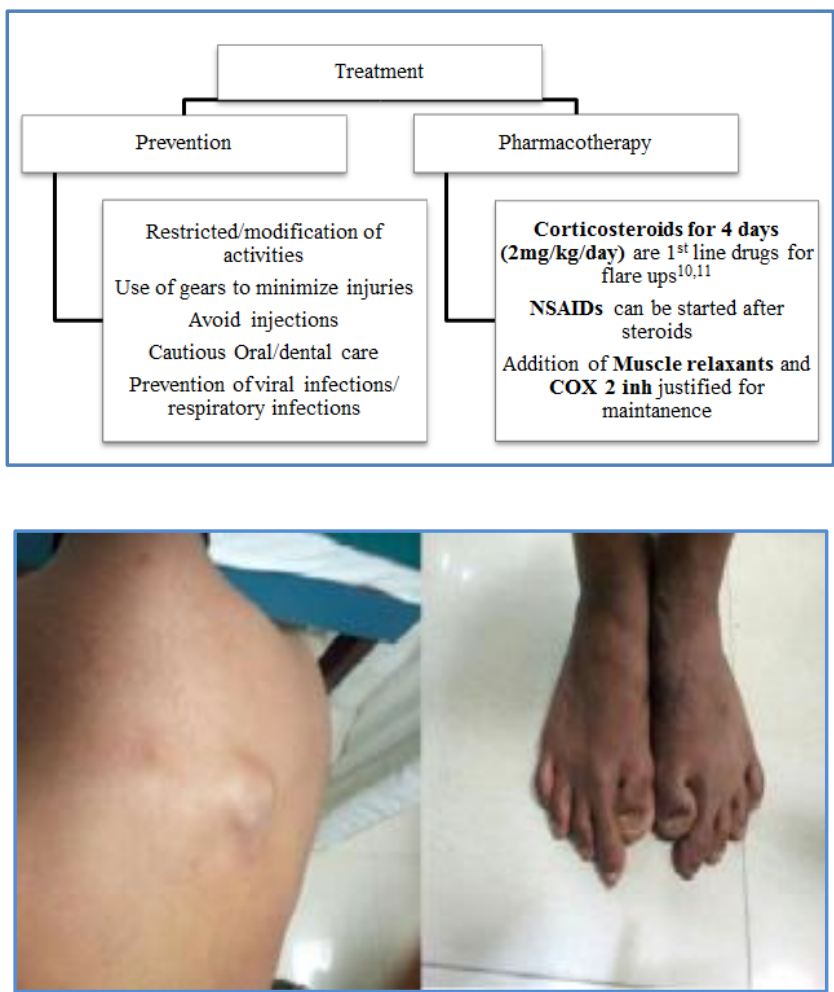

Figure 1: clinical images showing hard bony swelling in the dorsal parascapular region and hypoplastic great toes

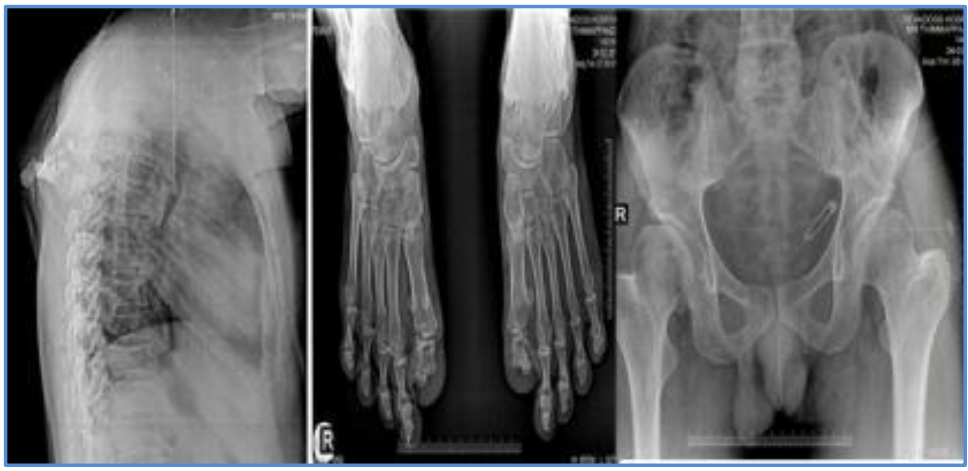

Fig. 2: radiographs revealing arthritic changes in the hip, ectopic ossification in the gluteal region and paraspinal region,hypoplastic 1st metatarsal and proximal phalanx 


\section{CASE REPORT}

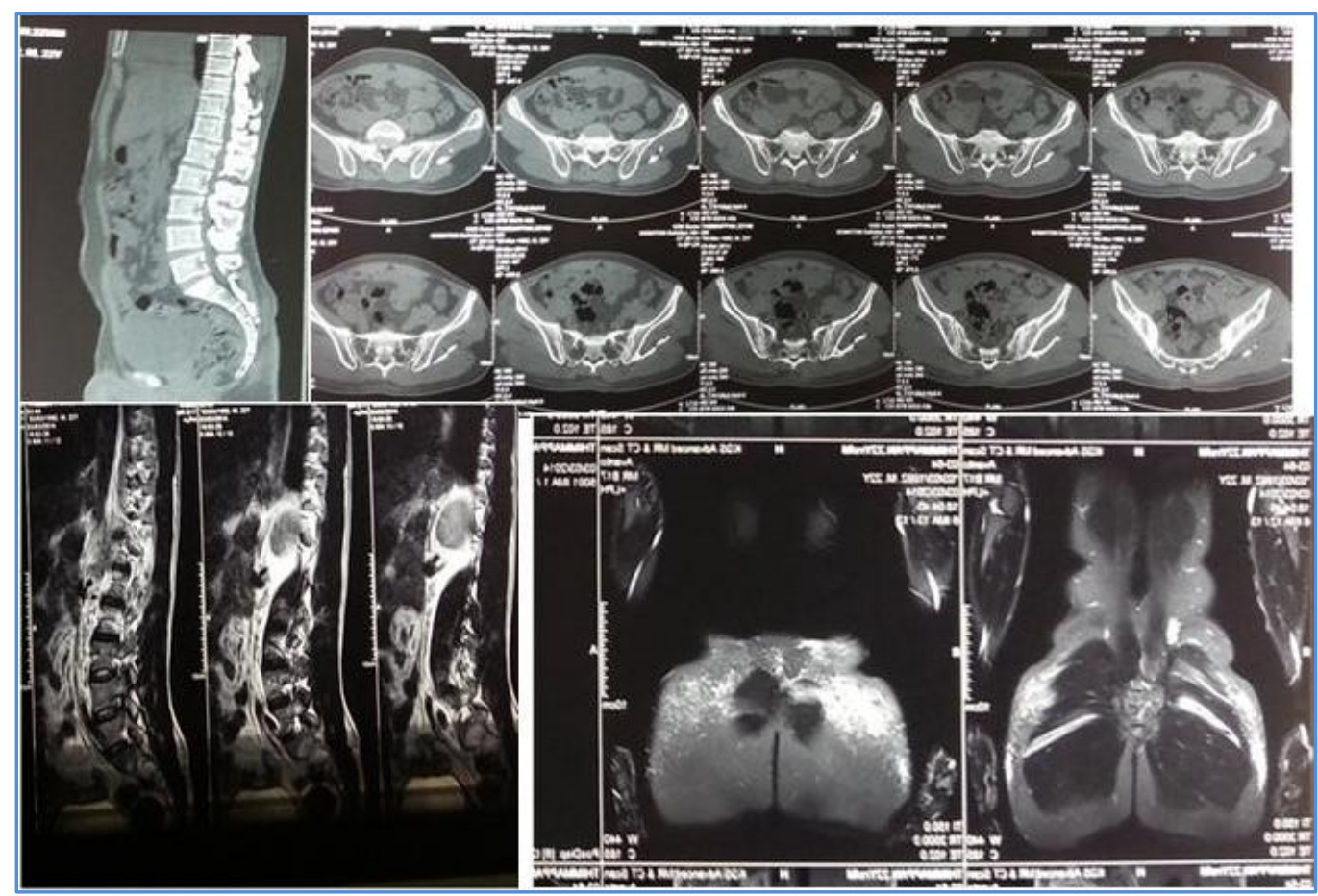

Fig. 3: CT\& MRI showing myositic changes involving left gluteal region and calcification of interspinous and supraspinous ligaments in lower thoracic and lumbar spine

\section{AUTHORS:}

1. R. K. Rohit

2. Madhuchandra P.

3. Sathish Devadoss

4. A. Devadoss

\section{PARTICULARS OF CONTRIBUTORS:}

1. Resident, Department of Orthopaedics, Devadoss Multispecialty Hospital, Madurai.

2. Consultant, Department of Orthopaedics, Devadoss Multispecialty Hospital, Madurai.

3. Consultant, Department of Orthopaedics, Devadoss Multispecialty Hospital, Madurai.

4. Consultant, Department of Orthopaedics, Devadoss Multispecialty Hospital, Madurai.

\author{
NAME ADDRESS EMAIL ID OF THE \\ CORRESPONDING AUTHOR: \\ Dr. Madhuchandra. P, \\ No. $757,5^{\text {th }}$ Main Road, \\ Vikrama Nagara, \\ ISRO Layout, \\ Bangalore-560078, \\ Karnataka. \\ Email: drmadhuchandrap@gmail.com
}

Date of Submission: 21/09/2014.

Date of Peer Review: 22/09/2014.

Date of Acceptance: 14/10/2014.

Date of Publishing: 27/10/2014. 